\title{
Static analysis of P-FGM beams resting on the Winkler elastic foundations
}

\author{
Boukhelf Fouad $^{1 *}$, Bachir B. Mohamed ${ }^{1,2,3}$, Boukhari Ahmed², Tounsi Abdelouahed ${ }^{2,3}$, Adda B. El- \\ abess $^{2}$ Liabes University of SIDI BEL ABBES,Algeria.
${ }^{2}$ Laboratory of Materials and hydrology, Djillali Liabes University of SIDI BEL ABBES,Algeria.
${ }^{3}$ Agence Thématique de Recherche Scientifique et Technologique ATRST (Algeria). \\ ${ }^{1}$ Laboratory of Structures and materials advances in the Civil Engineering and public works, Djillali
}

Email: fouad.boukhelf@hotmail.com

\begin{abstract}
In this paper investigates bending behavior of P-FGM beam resting on the elastic foundation including Winkler springs. Exact solutions obtained from closed-form formulation based on generalized shear deformation beam theory which can be adapted to various beams theories for bending analysis of such beam are presented. An accuracy of the present solutions is validated numerically by comparisons with some available results in the literature. Various significant parameters P-FGM volume fraction, spring constant factors, beam thickness, etc. are taken into investigation. According to the numerical results, it is revealed that the deflection of the beams is found to decrease as the increase of spring constant factors.
\end{abstract}

Keywords: P-FGM Beams, Winkler Elastic Foundation, Neutral Surface, Bending, Higher-order Theory.

\section{INTRODUCTION}

Functionally graded material (FGM) is a new class of composite material whose compositions vary according to the required performance. It is produced by a continuously graded variation of the volume fractions of the constituents (Koizumi 1997) [1], the FGM is thus suitable for various applications, such as thermal coatings of barrier for ceramic engines, gas turbines, nuclear fusions, optical thin layers, biomaterial electronics, etc.

Due to increasing of FGM applications in engineering structures, many beam theories have been developed to predict the response of functionally graded (FG) beams (HuuTai Thai 2012) [2]. The classical beam theory (CBT) known as Euler-Bernoulli beam theory is the simplest one and is applicable to slender FG beams only. For moderately deep FG beams, the CBT underestimates deflection and overestimates natural frequency due to ignoring the transverse shear deformation effect (Yang J, 2008) [3] (Alshorbagy 2011) [4]. The first-order shear deformation beam theory (FBT) known as Timoshenko beam theory has been proposed to overcome the limitations of the CBT by accounting for the transverse shear deformation effect. Since the FBT violates the zero shear stress conditions on the top and bottom surfaces of the beam, a shear correction factor is required to account for the discrepancy between the actual stress state and the assumed constant stress state(Chakraborty A, 2003) [5] (Wei D, 2012) [6] To avoid the use of a shear correction factor and have a better prediction of response of FG beams, higher-order shear deformation theories have been proposed, notable among them are the third-order theory of Reddy Reddy JN. 1984 [8-12], the sinusoidal theory of Touratier [13], the hyperbolic theory of Soldatos [14], the exponential theory of Karama et al. [15], and the unified formulation of Carrera [16,17]. Higher order shear deformation theories can be developed based on the assumption of a higher-order variation of axial displacement through the depth of the beam [18-19] or both axial and transverse displacements through the depth of the beam (i.e., via the use of a unified formulation) [20-21].

In this paper, a new model of higher-order shear deformation beam theories for bending of FG beams are developed based on the neutral axe (BOUKHARI 2016) [7], [23] and higher-order variation of axial displacement through the depth of the beam resting on elastic foundation (type winkler). The proposed theories satisfy the zero traction boundary conditions on the top and bottom surfaces of the beam, thus a shear correction factor is not required. In addition, these theories have strong similarities with the CBT in many aspects such as equations of motion, boundary conditions, and stress resultant expressions. Material properties of FG beams are assumed to vary according to a power law distribution of the volume fraction of the constituents. Equations of motion and boundary conditions are derived from Hamilton's principle. Analytical solutions for bending are obtained for a simply supported beam. Numerical examples are presented to show the validity and accuracy of present shear deformation theories. The effects of power law index and spring factors on the bending responses of FG beams are investigated. 


\section{MODEL ANALYTIC}

The model used is a beam FG with length $\mathrm{L}$ and rectangular cross section $\mathrm{b} \times \mathrm{h}$, with $\mathrm{b}$ being the width and $\mathrm{h}$ being the height. The $\mathrm{x}, \mathrm{y}$, and $\mathrm{z}$ coordinates are taken along the length, width, and height of the beam, respectively.

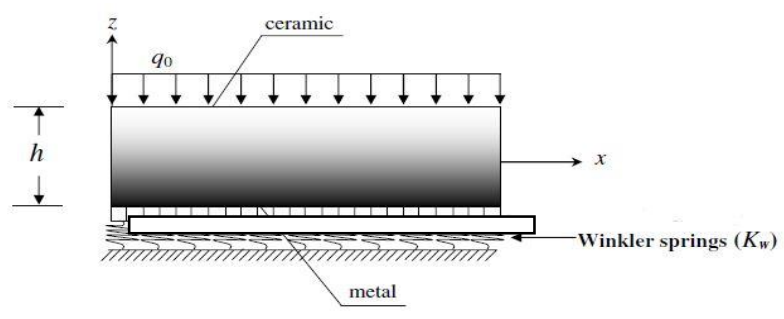

Figure 1. Geometry and coordinate system for a rectangular FG beam resting on winkler elastic foundations.

The $\mathrm{x}$ axis is considered indeformable of the beam axis. The $\mathrm{x}$ axis coincides with the median axis of the beam and the $\mathrm{z}$ axis is perpendicular to the $\mathrm{xy}$ plane. Because of the asymmetry of the material properties of the FG beams from the centerline, membrane and bending equations are coupled. But if the origin of the coordinate system is properly selected through the direction of the thickness of the FG beam in a way that it is positioned on the neutral axis, the material properties of the FG beam will be symmetrical about this reference. To specify the position of the neutral axis of the FG beam; different references are considered to measure $\mathrm{z}$ to know and measured from the centerline and the neutral axis of the beam is shown in figure 2 .

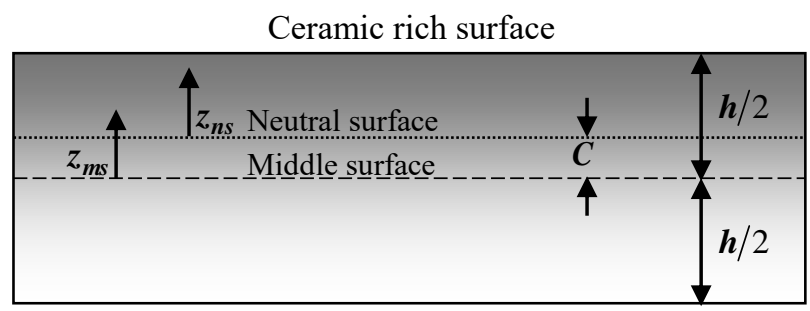

Metal rich surface

Figure 2.The position of midlle surface and neutral surface for a functionnall graded beams (BOUKHARI A.2016) [7],[23].

The material properties of the FG beam based on the coordinate of the thickness.

$P(z)=P_{M}+\left(P_{C}-P_{M}\right)\left(\frac{z_{n s}+C}{h}+\frac{1}{2}\right)^{p}$

The position of the neutral axis of the beam FG is determined from (Bouremana et al, 2013 [10]; Ould Larbi et al, 2013 [11]),Therefore, the position of the neutral axis can be obtained by.

$$
C=\frac{\int_{-h / 2}^{h / 2} E\left(z_{m s}\right) z_{m s} d z_{m s}}{\int_{-h / 2}^{h / 2} E\left(z_{m s}\right) d z_{m s}}
$$

The displacement fields of the present model of higherorder shear deformation beam theories are given in a general form as.

$$
\begin{aligned}
& u\left(x, z_{n s}\right)=u_{0}(x)-\left(z_{n s}+c\right) \frac{\partial w_{b}}{\partial x}-f\left(z_{m z}\right) \frac{\partial w_{s}}{\partial x} \\
& w\left(x, z_{n s}\right)=w_{b}(x)+w_{s}(x)
\end{aligned}
$$

where $u$ is the axial displacement of a point on the midplane of the beam; $w_{b}$ and $w_{s}$ are the bending and shear components of transverse displacement of a point on the midplane of the beam; and $f(z)$ is a shape function determining the distribution of the transvese shear strain and shear stress through the depth of the beam. The shape functions $f(z)$ are choosen to satisfy the stress-free boundary conditions on the top and bottom surfaces of the beam.

$f\left(z_{m s}\right)=\frac{\frac{h \sinh \left(\frac{\pi\left(z_{n s}+c\right)}{h}\right)}{\pi}-\left(z_{n s}+c\right)}{\cosh \left(\frac{\pi}{2}\right)-1}$

Les déformations non nulles sont données .

$\varepsilon x=\frac{\partial u_{0}}{\partial x}-\left(z_{n s}+c\right) \frac{\partial^{2} w_{b}}{\partial x^{2}}-f\left(z_{m s}\right) \frac{\partial^{2} w_{s}}{\partial x^{2}}$
$\gamma_{x z}=g\left(\mathrm{z}_{\mathrm{ms}}\right) \frac{\partial w_{s}}{\partial x}$

while $g\left(z_{m s}\right)=1-\frac{\partial f\left(z_{m s}\right)}{\partial z_{m s}}$

The linear constitutive relationships of the FG beams can be written as

$$
\begin{aligned}
& \sigma_{x}=Q_{11} \varepsilon_{x}, \tau_{x z}=Q_{55} \gamma_{x z} \\
& Q_{11}=E\left(z_{m s}\right), Q_{55}=\frac{E\left(z_{m s}\right)}{2(1+v)}
\end{aligned}
$$

\section{EQUATION OF MOTION}

The equilibrium equations are obtained using the principle of virtual displacements is applied to derive the equations of equilibrium and natural boundary conditions of a beam.

$\delta U+\delta V-f_{e}=0$

$\delta U$ is the virtual variation of strain energy;

$\delta V$ is the virtual variation of the work of external forces;

$f_{e}$ is the density of reaction force of the foundation.

$\delta U=\int_{V}\left(\sigma_{x} \delta \varepsilon_{x}+\tau_{x z} \delta \gamma_{x z}\right) d v$ 
$\delta V=-\int_{A} q \delta w d A$

$$
f_{e}=K_{w} w
$$

La solution de Navier est utilisée pour déterminer les solutions analytiques pour les poutres simplement appuyées. La solution est supposée comme suit .

$$
\begin{aligned}
& u(x)=\sum_{n=1}^{\infty} U_{n} \cos (\alpha x) \\
& w_{b}(x)=\sum_{n=1}^{\infty} W_{b n} \sin (\alpha x) \\
& w_{s}(x)=\sum_{n=1}^{\infty} W_{s n} \sin (\alpha x)
\end{aligned}
$$

$\alpha=n \pi / L ;\left(U_{n}, W_{b n}, W_{s n}\right)$ are unknowns who represent the amplitudes. The transverse load $\mathrm{q}$ is also developed in Fourier series as follows.

$$
\begin{aligned}
& q(x)=\sum_{n=1}^{\infty} Q_{n} \sin (\alpha x) \\
& Q_{n}=\frac{4 q_{0}}{n \pi} \quad(n=1,3,5 \ldots)
\end{aligned}
$$

Analytical solutions can be obtained in the following condensed form.

$\left[\begin{array}{ccc}s_{11} & s_{12} & s_{13} \\ s_{12} & s_{22} & s_{23} \\ s_{13} & s_{23} & s_{33}\end{array}\right]\left\{\begin{array}{l}U_{n} \\ W_{b n} \\ W_{s n}\end{array}\right\}=\left\{\begin{array}{c}0 \\ Q_{n} \\ Q_{n}\end{array}\right\}$

where

$$
\begin{aligned}
& s_{11}=A \alpha ? s_{12}=0, s_{13}=-B_{s} \alpha^{3} \\
& s_{22}=D \alpha^{4}+K_{w}, s_{23}=D_{s} A^{4}, \\
& s_{33}=H_{s} \alpha^{4}+A_{s} \alpha^{2}+K_{w} \\
& \left(A, B_{s}\right)=\int_{-h / 2}^{h / 2} Q_{11}\left(1, f\left(z_{n s}\right)\right) d z ; \\
& \left(D, D_{s}\right)=\int_{-h / 2}^{h / 2} Q_{11}\left(z_{n s}+c\right)\left(\left(z_{n s}+c\right), f\left(z_{n s}\right)\right) d z ; \\
& H_{s}=\int_{-h / 2}^{h / 2} Q_{11} f\left(z_{n s}\right) ? d z A_{s}=\int_{-h / 2}^{h / 2} Q_{55} g\left(z_{n s}\right) ? d z
\end{aligned}
$$

\section{DISCUSSION OF RESULTS}

In this study, bending analysis of simply supported FG beams subjected a uniform load resting in elastic foundation of the type Winkler' by using the hyperbolic shear deformation beam theory is suggested for investigation. Comparisons are made with available solutions in literature. In order to verify the accuracy of the present analysis, some numerical examples are solved. The first comparison of the power law modeling is given through comparison with elasticity solutions available in literature (Huu-Tai Thaiet al 2012) [1], (Lie et al 2010 [22]) give numerical results for the transverse deflections and stresses in an isotropic plate with power law variation in modulus subject to sinusoidal loading of the form. The material properties of the FGM are indicated in Table 1.

Table1. Nondimensional deflections and stresses of FG beams under uniform load without elastic foundation.

\begin{tabular}{llcccc}
\hline \multirow{2}{*}{ P Theory } & $\overline{4}$ & $\bar{u}$ & $\bar{\sigma}_{x}$ & $\bar{\sigma}_{x z}$ \\
\hline \multirow{2}{*}{ Li et al. } & 3.1657 & 0.9402 & 3.802 & 0.75 \\
TBT & 3.1654 & 0.9398 & 3.802 & 0.7332 \\
SBT & 3.1649 & 0.9409 & 3.8053 & 0.7549 \\
0 & HBT & 3.1654 & 0.9397 & 3.8017 & 0.7312 \\
EBT & 3.1635 & 0.9420 & 3.8083 & 0.7763 \\
CBT & 2.8783 & 0.9211 & 3.75 & - \\
Present & 3.1651 & 0.9387 & 3.7991 & 0.7149 \\
\hline Li et al. & 6.2599 & 2.3045 & 5.8837 & 0.75 \\
TBT & 6.2594 & 2.3038 & 5.8836 & 0.7332 \\
SBT & 6.2586 & 2.3058 & 5.8892 & 0.7549 \\
HBT & 6.2594 & 2.3036 & 5.8831 & 0.7312 \\
EBT & 6.2563 & 2.3075 & 5.8943 & 0.7763 \\
CBT & 5.7746 & 2.2722 & 5.7959 & - \\
Present & 6.2590 & 2.3021 & 5.8789 & 0.7149 \\
\hline Li et al. & 9.7802 & 3.7089 & 8.103 & 0.579 \\
TBT & 9.8281 & 3.71 & 8.1106 & 0.5905 \\
SBT & 9.8367 & 3.714 & 8.1222 & 0.6155 \\
HBT & 9.8271 & 3.9097 & 8.1095 & 0.5883 \\
EBT & 9.8414 & 3.7177 & 8.1329 & 0.6404 \\
CBT & 8.7508 & 3.6496 & 7.9428 & - \\
Present & 9.8181 & 3.7066 & 8.1008 & 0.5697 \\
\hline Li et al. & 10.8979 & 3.886 & 9.7063 & 0.6436 \\
TBT & 10.9381 & 3.8864 & 9.7122 & 0.6467 \\
EBT & 10.942 & 3.8913 & 9.7238 & 0.6708 \\
CBT & 10.9375 & 3.8859 & 9.7111 & 0.6445 \\
Present & 10.9312 & 3.8821 & 9.7023 & 0.6263 \\
\hline
\end{tabular}

For numerical results, an $\mathrm{Al} / \mathrm{Al} 2 \mathrm{O} 3$ beam composed of aluminum (as metal) and alumina (as ceramic) is considered. The material properties of aluminum are $E_{m}=70 \mathrm{GPa}, \rho_{m}=2702 \mathrm{Kg} / \mathrm{m}^{3}, v=0.3$ and those of alumina are $E_{c}=380 \mathrm{GPa}, \rho_{c}=3960 \mathrm{Kg} / \mathrm{m}^{3}$ (sismek2009) [9].

For convenience, the following dimensionless forms are used.

$$
\begin{aligned}
& \bar{w}=100 \frac{E_{m} h^{3}}{q_{0} L^{4}} w(L / 2) \\
& \bar{u}=100 \frac{E_{m} h^{3}}{q_{0} L^{4}} u(0,-h / 2) \\
& \bar{\sigma}_{x}=\frac{h}{q_{0} L} \sigma_{x}(L / 2, h / 2) \\
& \bar{\tau}_{x z}=\frac{h}{q_{0} L} \tau_{x z}(0,0) ; K_{w}=\frac{k_{w} D D}{L^{2}} ; D D=\frac{E_{c} h^{3}}{12\left(1-v^{2}\right)}
\end{aligned}
$$




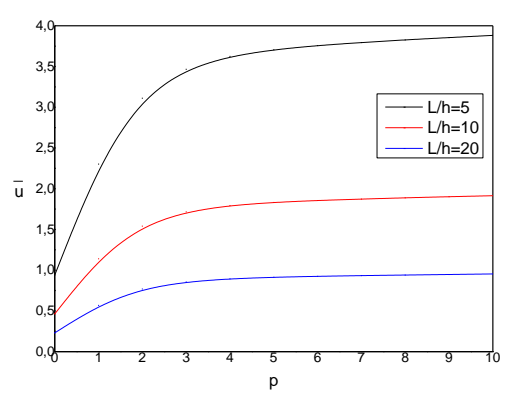

Figure 3. Variation of nondimensional axial displacement $\bar{u}$ with respect to the power law index $p$ for FG beams under uniform load without elastic foundation.

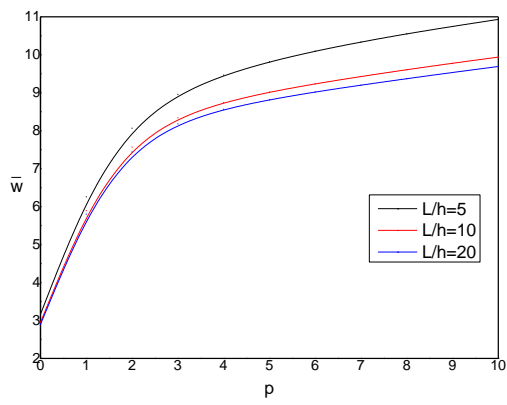

Figure 4. Variation of nondimensional transverse deflection $w$ with respect to the power law index $p$ for FG beams under uniform load without elastic foundation.

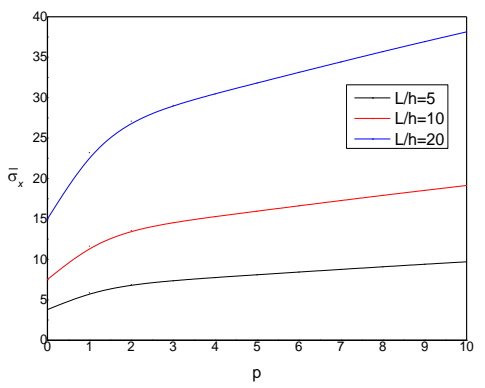

Figure 5. Variation of nondimensional axial normal stress

$\sigma_{x}$ with respect to the power law index $p$ for FG beams under uniform load without elastic foundation.

To illustrate the effect of power law index $p$ on the bending response of FG beams under uniform load, the axial displacement $\bar{u}$, transverse deflection $\bar{w}$, and axial stress $\overline{\sigma_{x}}$, respectively are plotted in Figs. 3-4 and 5. Since there are no differences between the results of shear deformation beam theories, TBT is used only in Figs. 3-4 and 5. It can be seen that increasing the power law index $p$ will reduce the stiffness of the FG beams, and consequently, leads to an increase in the deflections and axial stress. This is due to the fact that higher values of power law index $p$ correspond to high portion of metal in comparison with the ceramic part, thus makes such FG beams more flexible.

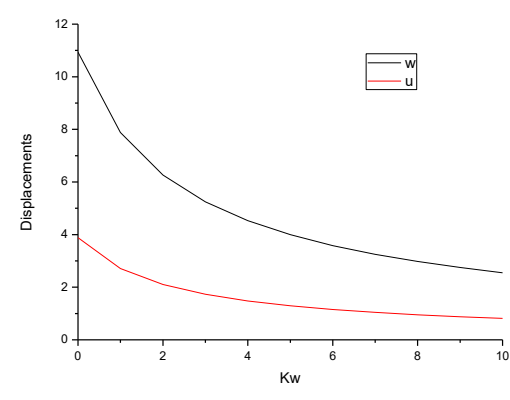

Figure 6. Variation of displacements adimensionnaless $\bar{u}$ and $\bar{w}$ with elastic foundation $p=10, a / h=5$.

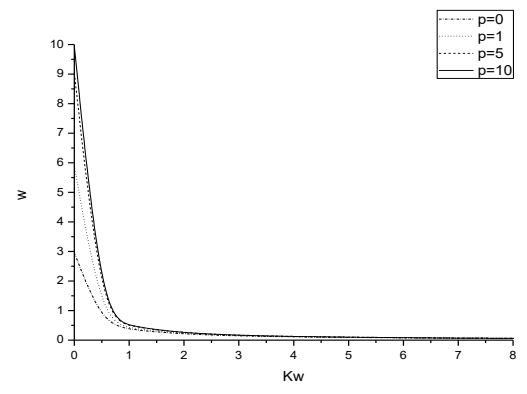

Figure 7. Variation of displacements adimensionnaless $\bar{w}$ with elastic foundation, $a / h=10$.

The effect of elastic foundation factor $K_{w}$ on the nondimensionals displacements $\bar{u}$ and $\bar{w}$ of $\mathrm{FG}$ beams is shown in Fig. 6. It is observed that an increase in the value of the elastic foundation factor $K_{w}$ leads to a reduction of the displacements for $p=10, a / h=5$.

Fig. 7 contains the nondimensional deflections for different value of the power law index $p$ results in a decrease in the value of elasticity modulus and the effect of elastic foundation. In other words, the beam becomes flexible as the power law index increases, thus decreasing the displacements values.

\section{CONCLUSIONS}

In this research the new high order shear deformation theory based on the concept of the neutral axis FG has been studied, and several numerical examples were presented and discussed to check the accuracy of the latter. The results obtained by the proposed theory are almost identical and are similar good results of the literature. There was an increase in the arrow and a reduction of the transverse deflection, this is due to the material increase, to the inclusion of the effects of shear deformation and to the factor of the elastic foundation.

\section{ACKNOWLEDGMENT}

This research was supported by the thematic research agency of science and technology ATRST (Algeria). and Djillali Liabes University. 


\section{REFERENCES}

[1] Koizumi M. (1993). The concept of FGM, ceramic transactions, Function. Grad. Mater, Vol. 34, pp. 3-10.

[2] Thai H.T. (2012). Bending and free vibration of functionally graded beams using various higher-order shear deformation beam, International Journal of Mechanical Sciences, Vol. 62, pp. 57-66.

[3] Yang J., Chen Y. (2008). Free vibration and buckling analyses of functionally gradedbeams with edge cracks, Compos Struct, Vol. 83, No. 1, pp. 48-60.

[4] Alshorbagy A.E., Eltaher M., Mahmoud F. (2011). Free vibration characteristics of a functionally graded beam by finite element method, Appl Math Modell, Vol. 35, No. 1, pp. 412-25.

[5] Chakraborty A., Gopalakrishnan S., Reddy J.N. (2003). A new beam finite element for the analysis of functionally graded materials, Int J Mech Sci, Vol. 45, No. 3, pp.519-39.

[6] Wei D., Liu Y., Xiang Z. (2012). An analytical method for free vibration analysis of functionally graded beams with edge cracks, J Sound Vib, Vol. 331, No. 7, pp. 1686-700.

[7] Boukhari A. (2016). An efficient shear deformation theory for wave propagation of fonctionnally graded material plates, Structural Engineering and Mechanics, Vol. 57, No. 5837-859. DOI: 10.12899/sem.2016.57.5.837

[8] Reddy J.N. (1984). A simple higher-order theory for laminated composite plates, J Appl Mech, Vol. 51, No. 4, pp. 745-52.

[9] Simsek M., Kocaturk T. (2009). Free and forced vibration of a functionally graded beam subjected to a concentrated moving harmonic load, Compos Struct, Vol. 90, No. 4, pp. 465-73.

[10] Bouremana M., Houari M.S.A., Tounsi A., Kaci A., Adda B.E.A. (2013). A new first shear deformation beam theory based on neutral surface position for functionally graded beams, Steel and Composite Structures, Vol. 15, No. 5, pp. 467-479.

[11] Ould L.L., Kaci A., Houari M.S.A., Tounsi A. (2013). An efficient shear deformation beam theory based on neutral surface position for bending and free vibration of functionally graded beams, Mechanics Based Design of Structures and Machines, Vol. 41, pp. 421433.

[12] Yesilce Y., Catal H.H. (2011). Solution of free vibration equations of semi-rigid connected ReddyBickford beams resting on elastic soil using the differential transform method, Arch Appl Mech, Vol. 81, No. 2, pp. 199-213.

[13] Touratier M. (1991). An efficient standard plate theory, Int J Eng Sci, Vol. 29, No. 8, pp. 901-16.

[14] Soldatos K. (1992). A transverse shear deformation theory for homogeneous monoclinic plates, Acta Mech, Vol. 94, No. 3, pp. 195-220.

[15] Karama M., Afaq K.S., Mistou S. (2003). Mechanical behavior of laminated composite beam by the new multi-layered laminated composite structures model with transverse shear stress continuity, Int J Solids Struct, Vol. 40, No. 6, pp. 1525-46.
[16] Carrera E. (2003). Theories and finite elements for multilayered plates and shells. a unified compact formulation with numerical assessment and benchmarking, Arch Comput Meth Eng, Vol. 10, No. 3, pp. 215-96.

[17] Carrera E., Giunta G., Petrolo M. (2011). Beam structures: classical and advanced theories, West Sussex, UK: John Wiley \& Sons, Ltd.

[18] Aydogdu M., Taskin V. (2007). Free vibration analysis of functionally graded beams with simply supported edges, Mater Des, Vol. 28, No. 5, pp. 1651-6.

[19] Wattanasakulpong N., Gangadhara P.B., Kelly D.W. (2011). Thermal buckling and elastic vibration of third-order shear deformable functionally graded beams, Int J Mech Sci, Vol. 53, No. 9, pp.734-43.

[20] Giunta G., Belouettar S., Carrera E. (2010). Analysis of FGM beams by means of classical and advanced theories, Mech Adv Mater Struct, Vol. 17, No. 8, pp. 622-35.

[21] Giunta G., Crisafulli D., Belouettar S., Carrera E. (2011). Hierarchical theories for the free vibration analysis of functionally graded beams, Compos Struct, Vol. 94, No.1, pp. 68-74.

[22] Li X.F., Wang B.L., Han J.C. (2010). A higher-order theory for static and dynamic analyses of functionally graded beams, Arch Appl Mech, Vol. 80, No. 10, pp. 1197-212.

[23] Ahmed B., Fouad B., Djalil B.A., Mohamed B.B., Abdelouahed T., Bedia E.A. (2016). The thermal study of wave propagation in functionally graded material plates (FGM) based on neutral surface position, Mathematical Modelling of Engineering Problems, Vol. 3, No. 4, pp. 202-205. DOI: 10.18280/mmep.030410

\section{NOMENCLATURE}

$\mathrm{L}$

b

$\mathrm{h}$

$\mathrm{x}, \mathrm{y}, \mathrm{z}$

$\mathrm{u}, \mathrm{w}$

$Z_{\text {ns }}$

$\mathrm{C}$

E

$\mathrm{P}_{\mathrm{M}, \mathrm{P}_{\mathrm{C}}}$

\section{Greek symbols}

$\begin{array}{ll}\sigma_{\mathrm{x}} & \text { Normal stress } \\ \varepsilon_{\mathrm{x}} & \text { Deformation. } \\ \gamma_{\mathrm{xz}} & \text { The distortion } \\ \tau_{\mathrm{xz}} & \text { Transverse shear stress } \\ \mathrm{u} & \text { Poisson's ratio }\end{array}$

\section{Subscripts}

Length of the beam

Width of the beam

Height of the beam thermal conductivity, The Cartesian coordinate system

Displacements in $\mathrm{x}$ and $\mathrm{z}$.

The position of the neutral axis.

The distance from the neutral axis to the centerline

The modulus of elasticity

The properties of the metal and ceramic 